\title{
Association of the Small GTPase Rheb with the NMDA Receptor Subunit NR3A
}

\author{
Nikolaus J. Sucher ${ }^{a-c}$ Eric Yu ${ }^{d}$ Shing Fai Chan ${ }^{d}$ Mitra Miri $^{b}$ Benjamin J. Lee $^{b}$ \\ Bo Xiao ${ }^{\text {e }}$ Paul F. Worley ${ }^{e}$ Frances E. Jensen ${ }^{b, c, f}$ \\ ${ }^{a}$ Centre for Complementary Medicine Research, University of Western Sydney, Penrith South DC, N.S.W., Australia; \\ ${ }^{b}$ Department of Neurology, Division of Neuroscience, Children's Hospital, and 'Department of Neurology, \\ Harvard Medical School, Boston, Mass., 'Sanford-Burnham Medical Research Institute, La Jolla, Calif. \\ e Department of Neuroscience, Johns Hopkins University School of Medicine, Baltimore, Md., and ${ }^{\mathrm{f}}$ Program in \\ Neuroscience, Harvard Medical School, Boston, Mass., USA
}

\section{Key Words}

NMDA receptor $\cdot$ Rheb $\cdot$ Synapse $\cdot$ Plasticity $\cdot$ Translation $\cdot$ mTOR

\begin{abstract}
The NMDAR subunit NR3A is most highly expressed during the second postnatal week, when synaptogenesis reaches peak levels. Genetic ablation or overexpression of the NR3A subunit negatively interferes with the maturation of cortical synapses and leads to changes in the shape and number of dendritic spines, the density of which is increased in NR3A knock-out mice and decreased in NR3A-overexpressing transgenic mice. Alterations in spine density have been linked to dysregulation of mTOR signaling and synaptic protein translation. Using a yeast two-hybrid system, we identified the mTOR-activating GTPase Rheb as an interacting protein of the NMDAR subunit NR3A. We confirmed the interaction in mammalian cells by expressing recombinant Rheb and NR3A and showed that Rheb and NR3A could be co-immunoprecipitated from synaptic plasma membranes from the developing rat brain. These data suggest that NR3A sequesters synaptic Rheb and might thus function as a break of the mTOR-dependent synaptic translation of protein.
\end{abstract}

Copyright $\odot 2010$ S. Karger AG, Basel

\section{Introduction}

Glutamatergic synapses are sites of expression of the molecular and structural changes underlying learning and memory in the central nervous system. The experience and activity-dependent refinement of synaptic connections is commonly referred to as synaptic plasticity [1]. Functionally, synaptic plasticity is expressed as long-term potentiation (LTP) and long-term depression (LTD), longlasting enhancement and weakening of the activity of synapses, respectively [2]. Structurally, synaptic plasticity is evident in the changing shape and size of the postsynaptic dendritic spines [3]. At the molecular level, synaptic plasticity is dependent on the activation of the $\mathrm{N}$-methylD-aspartate receptor (NMDAR) subtype of glutamate receptors (GluRs) and increased dendritic protein synthesis [4]. NMDARs are heteromeric complexes composed of NR1 and NR2 subunits (NR2A-NR2D) and in some cases additional NR3 subunits (NR3A or NR3B) [5]. The subunit composition of NMDARs is developmentally regulated and influenced by neuronal activity and sensory experience [6]. In rodents, NR3A is most highly expressed during the second postnatal week, when synaptogenesis reaches peak levels $[7,8]$. Deletion or overexpression of NR3A interfered with the maturation of cortical synapses

\section{KARGER}

Fax +4161306 1234

E-Mail karger@karger.ch

www.karger.com
(C) 2010 S. Karger AG, Basel

Accessible online at: www.karger.com/nsg
Prof. Nikolaus I. Sucher

The Centre for Complementary Medicine Research

University of Western Sydney, Locked Bag 1797

Penrith, NSW 2751 (Australia)

Tel. +61 24620 3345, Fax +61 24620 3017, E-Mail n.sucher@ uws.edu.au 
and led to changes in the shape and number of dendritic spines, the density of which was increased in NR3A knockout mice and decreased in NR3A-overexpressing transgenic mice [8-10]. The molecular mechanism coupling NR3A to regulation of dendritic spine density is not known. Possible clues, however, can be gained from another condition in which increased spine number is a hallmark, namely fragile X syndrome (FXS). Inactivation of the X-linked FMR1 gene and the resulting absence of its gene product fragile $\mathrm{X}$ mental retardation protein (FMRP) cause the most common inherited form of cognitive deficiency in humans. FMRP is an RNA-binding protein that specifically binds to and regulates the translation of certain mRNAs at excitatory synapses [11]. FXS is therefore considered to be primarily a disease of dysregulated mRNA translation and protein-synthesis-dependent synaptic plasticity [12]. Recent results indicate that the activity of FMRP is dependent on its phosphorylation status, which is under bidirectional control of signaling module involving the ribosomal protein S6 kinase (S6K1) and the serine-threonine protein phosphatase PP2A [13, 14]. $\mathrm{PP} 2 \mathrm{~A}$ is activated upon stimulation of the metabotropic glutamate receptor (mGluR) 5, and S6K1 and PP2A activity are both modulated via the signaling pathway involving the mammalian target of rapamycin (mTOR), a central control switch of protein synthesis [15]. As PP2A was previously shown to form a signaling complex with NMDARs via interaction between its catalytic subunit and the NMDAR subunit NR3A [16], we wondered whether changes in dendritic spine density observed upon deletion or overexpression of NR3A might be mediated via its interaction with the machinery controlling dendritic protein synthesis. Here we report that NR3A interacts with the small GTPase Ras homologue enriched in brain (Rheb). Rheb expression is increased by NMDAR-mediated synaptic activity [17] and has recently been shown to stimulate the activity of the mTOR signaling complex 1 (TORC1), leading to increased protein translation [15]. Together, these data indicate that NR3A constitutes a physical link between NMDARs and a critical regulator of protein translation, Rheb and suggest a role for NR3A containing NMDARs in protein-translation-dependent dendritic spine density and synaptic plasticity.

\section{Materials and Methods}

Yeast Two-Hybrid Screen

A yeast two-hybrid screen, with the full-length intracellular C-terminus of NR3A (NR3Ac, Gly ${ }_{951}-\mathrm{Ser}_{1115}$ ) as bait, was performed as described in detail previously [16]. Briefly, NR3Ac was amplified by PCR and subcloned into the expression vector pEG202 in-frame with a LexA DNA-binding domain. This expression construct, together with a URA reporter plasmid and a human fetal brain cDNA library in plasmid pJG4-5, was transformed into yeast strain Saccharomyces cerevisiae EGY48 by the lithium acetate method to screen for associated proteins. The transformants were selected on the basis of the formation of (1) blue colonies on plates lacking uracil, histidine and tryptophan and containing 5-bromo-4-chloro-3-indolyl- $\beta$-D-galactosidase, and (2) LEU gene expression from a chromosomal lexAop-LEU reporter on plates without leucine. Expression of the lacZ reporter gene was determined by measuring $\beta$-galactosidase activity using 2-nitrophenyl- $\beta$-D-galactopyranoside as substrate. NR3Ac and two NR3A C-terminal deletions (NR3Ac-5, Val ${ }_{988^{-}}$Ser $_{1115}$; NR3Ac-6, Leu $_{1082}$-Ser ${ }_{1115}$ ) were transformed into yeast and assayed for $\beta$-galactosidase activity.

In vitro Protein-Binding Assays

The NR3Ac (amino acid residues 952-1,115), NR3Ac fragments and Rheb were amplified by PCR. The NR3Ac primers used were: 5'-CGCGGATCCATGGCTAGCATGACTGGTGGACAGC-3' and 5'-CCGCTCGAGCTAGGATTCACAAGTCCGATTTGTC-3'. The Rheb primers had the sequence: 5'-GGATTCCATATGCCTCAGTCCAAGTCCCGG-3' and 5'-CCGCTCGAGCTTTTCTGCTTCCAAAATTATCCTTC-3'. NR3Ac and NR3Ac fragments were subcloned into the pGEX-4T-1 vector (GE Healthcare Biosciences), and Rheb (residues 1-169) was subcloned into pET-21b (Novagen) for expression in Escherichia coli. Recombinant GST, GST-NR3Ac or its truncated proteins $(1 \mu \mathrm{g})$ were incubated with $1 \mu \mathrm{g}$ of Rheb-His at $25^{\circ} \mathrm{C}$ for $15 \mathrm{~min}$ in PBS. Glutathione Sepharose resin (10 $\mu \mathrm{l}$, GE Healthcare Biosciences) was then added to the mixture. The GST protein-bound resin was washed 3 times using PBS buffer plus $20 \mathrm{mM}$ imidazole and $0.1 \%$ Triton X-100, and all the associated proteins were boiled and analyzed by SDS-PAGE/immunoblotting using anti-His or anti-GST antibodies.

\section{Construction of Myc-Rheb}

Rheb was amplified by polymerase chain reaction (PCR) using the forward primer $5^{\prime}$-AGTCTAGACTATGCCTCAGTCCAAGTCCCGG-3' and reverse primer $5^{\prime}$-CGGAATTCTCACATCACCGAGCACGAAGACTT-3'. The PCR product was then cloned into the pcDNA3.1-myc-His A vector (Invitrogen).

Transfection of Human Embryonic Kidney (HEK) 293 Cells

HEK293T cells were transiently transfected with NR3A and Rheb expression constructs using calcium phosphate precipitation. Two days after transfection, cells were harvested and homogenized in RIPA buffer (150 mM sodium chloride, $1 \%$ NP- $40,0.1 \%$ deoxycholic acid, $0.05 \%$ SDS, $50 \mathrm{~mm}$ Tris- $\mathrm{HCl}, \mathrm{pH} 7.5,1 \mathrm{~mm}$ EDTA, pH 8, 1 mM EGTA and complete protease inhibitor; Roche).

\section{Preparation of Synaptic Plasma Membranes}

Tissue was collected from 10-day-old male Long-Evans rats (Charles River Laboratories). The rats were sacrificed by decapitation and their whole brains (including olfactory bulbs and cerebella) dissected aseptically. The brains were washed in ice-cold PBS and homogenized in $5 \mathrm{ml}$ homogenization buffer $(0.36 \mathrm{M} \mathrm{su}$ crose, 7 mM Tris pH 7.5, 0.5 M EGTA, 0.25 mM DTT, 1 mM NaF, 
$1 \mathrm{mM} \beta$-glycerol phosphate, $1 \mathrm{mM} \mathrm{Na}_{3} \mathrm{VO}_{4}$, Roche Complete protease inhibitor cocktail tablet) per brain using 12-14 strokes of a Potter-Elvehjem homogenizer (Wheaton). After adding another $5 \mathrm{ml}$ homogenization buffer ( $\mathrm{HB})$ per brain to the homogenates, they were spun at $1,500 \mathrm{~g}$ for $2 \mathrm{~min}$. The supernatant was then spun at 23,000 $\mathrm{g}$ for $6 \mathrm{~min}$. $1-2 \mathrm{ml}$ of the resulting pellet was collected as crude membranes (CM), dissolved in an equivalent volume of NP-40 lysis buffer (50 mM Tris- $\mathrm{HCl} \mathrm{pH} \mathrm{8.0,} 150 \mathrm{mM} \mathrm{NaCl}$, $1 \%$ NP-40, 5 mM EDTA, Roche Complete protease inhibitor cocktail tablet), re-homogenized with 2 strokes, and stored at $-80^{\circ} \mathrm{C}$. The remainder of the pellet was placed on top of a discontinuous Ficoll (Sigma) gradient consisting of 2 layers: a 13\% Ficoll/HB solution and a $5 \%$ Ficoll/HB solution. This gradient was spun at $45,000 \mathrm{~g}$ for $45 \mathrm{~min}$. Synaptic plasma membranes (SPM) were collected from the interface between the two Ficoll solutions, washed in ice-cold PBS, and spun at 23,000 $\mathrm{g}$ for $20 \mathrm{~min}$. The resulting pellets were re-suspended in an equivalent volume of NP-40 lysis buffer and stored at $-80^{\circ} \mathrm{C}$. Protein concentration of CM and SPM was determined by bicinchoninic acid protein assay (Sigma).

\section{Generation of Anti-Rheb Antibodies}

Rhebl polyclonal antibodies were generated by immunizing rabbits with mouse Rhebl-GST fusion protein. The specificity of the antibody was confirmed by blotting extracts of HEK293 cells that had been transfected with either Rheb1 or Rheb2, and brain extracts from Rheb1 knockout mice.

\section{Immunoprecipitation, Gel Electrophoresis, and \\ Immunoblotting}

For immunoprecipitation, protein A/G agarose (Santa Cruz) were added to HEK293 cell lysates to pre-clear the lysates. Primary antibodies $(10 \mu \mathrm{g} / \mathrm{ml})$ were then added and incubated overnight at $4{ }^{\circ} \mathrm{C}$, followed by $2 \mathrm{~h}$ incubation with protein $\mathrm{A} / \mathrm{G}$ agarose. Immunoprecipitates were eluted from the agarose in sample loading buffer (Invitrogen). Immunoprecipitates were analyzed by SDS-PAGE and immunoblotting after electrotransfer of proteins to polyvinylidene difluoride membranes. Antibodies used for immunoblotting and immunoprecipitation included anti-NR3A and c-myc (cell signaling).

The Seize X Protein G Immunoprecipitation Kit (Pierce) was used to crosslink the antibodies to Immobilized Protein G Plus agarose beads. Bead slurry $(400 \mu \mathrm{l}$ of $50 \%)$ was centrifuged at $3,000 \mathrm{~g}$ for $1 \mathrm{~min}$ at RT. The beads were re-suspended in $300 \mu \mathrm{l}$ of bind/wash (B/W) buffer containing $100 \mu \mathrm{g}$ of antibody. This mixture was rocked for $15 \mathrm{~min}$ at room temperature (RT), centrifuged at 3,000 $\mathrm{g}$ for $1 \mathrm{~min}$ at RT, and then washed 3 times in $500 \mu \mathrm{l} \mathrm{B} / \mathrm{W}$ buffer. DSS crosslinker-in-DMSO mixture $(25 \mu \mathrm{l})$ was added, and the mixture was rocked for $60 \mathrm{~min}$ at RT. The mixture was then centrifuged at 3,000 $\mathrm{g}$ for $1 \mathrm{~min}$ at RT, and the beads were washed 5 times in $500 \mu \mathrm{l}$ of elution buffer, followed by 2 times in B/W buffer. B/W buffer $(200 \mu \mathrm{l})$ was added to the cross-linked beads, and $40 \mu \mathrm{l}$ of this $50 \%$ slurry was centrifuged at 3,000 $\mathrm{g}$ for $1 \mathrm{~min}$ at RT. The beads were then washed in $50 \mu \mathrm{lNP}-40$ lysis buffer and spun down at $500 \mathrm{~g}$ for $1 \mathrm{~min}$ at RT. The cross-linked beads were re-suspended in $20 \mu \mathrm{l} \mathrm{NP}-40$ lysis buffer and added to sample protein (1 to $5 \mathrm{mg}$ ). The samples were incubated on a rocker for $2 \mathrm{~h}$ at RT or overnight at $4^{\circ} \mathrm{C}$. The mixture was centrifuged at $5,000 \mathrm{~g}$ for $1 \mathrm{~min}$ at RT and washed 3 times in $50 \mu \mathrm{l} \mathrm{NP}-40$ lysis buffer. Antigen was eluted from the beads using $15 \mu$ l elution buffer added 3 consecutive times and collected as separate frac-

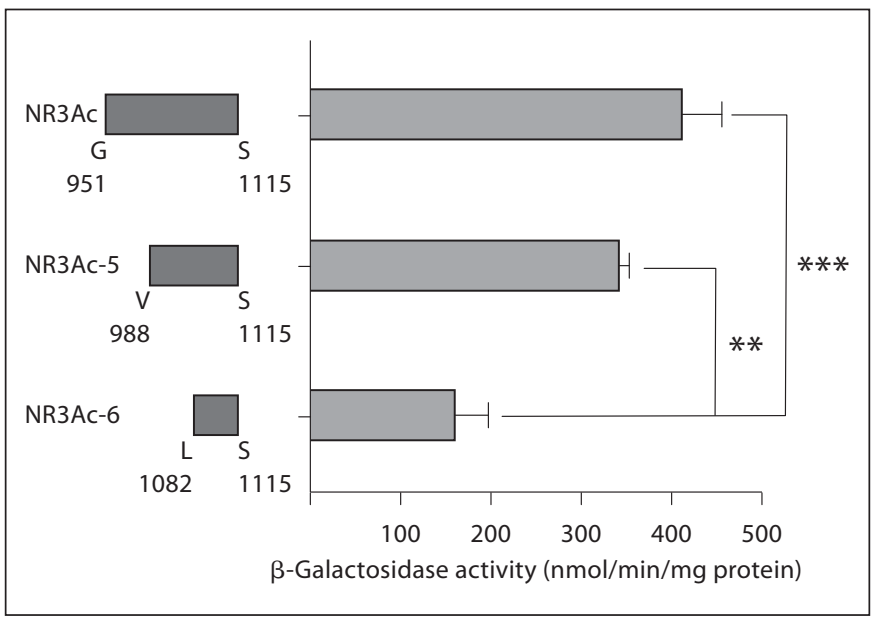

Fig. 1. Interaction of NR3A with Rheb in yeast. The intracellular C-terminus of NR3A (NR3Ac: Gly $951-$ Ser $_{1115}$ ) and two deletion constructs (NR3Ac-5 and NR3Ac-6) were used in a yeast twohybrid assay. The grey boxes correspond to the constructs used in the assay. Corresponding $\beta$-galactosidase activities of each construct on interaction with Rheb are summarized in the histogram. Binding of Rheb to NR3Ac- 6 was significantly decreased compared to NR3Ac and NR3Ac-5 ( $<<0.001$ and $p<0.01$, oneway analysis of variance followed by Tukey's multiple comparison test). The mean of the $\beta$-galactosidase activities from 3-4 experiments are given in nanomoles per minute per milligram of protein \pm SEM.

tions. The samples were heated at $95^{\circ} \mathrm{C}$ for $5 \mathrm{~min}$ and used immediately for SDS-PAGE gel electrophoresis or stored at $-20^{\circ} \mathrm{C}$ for later use. Immunoblotting was performed after transfer of proteins to polyvinylidene difluoride (PVDF) membranes using the iBlot (Invitrogen) dry blotting system. PVDF membranes were blocked in 5\% non-fat dry milk (NFDM)/Tris-base saline with $0.1 \%$ Tween 20 (TBST) for $1-2 \mathrm{~h}$, incubated in primary antibody (in $5 \% \mathrm{NFDM} / \mathrm{TBST}$ ) overnight at $4^{\circ} \mathrm{C}$, rinsed twice in TBST $(100$ $\mathrm{mM}$ Tris Base, $154 \mathrm{mM} \mathrm{NaCl}, 1 \mathrm{ml} / \mathrm{l}$ Tween 20), washed 3 times in TBST for 5 min each, and then incubated in secondary antibody (in 5\% NFDM/TBST) for $1 \mathrm{~h}$ at RT. The blots were visualized using the SuperSignal West Femto Chemiluminescence Substrate Kit (Pierce). The anti-NR3A antibodies were purchased from Chemicon International. Secondary antibodies used were horseradish peroxidase (HRP)-conjugated Goat Anti-Mouse IgG (Pierce; 1:10,000) and Goat Anti-Rabbit IgG (Pierce; 1:10,000).

\section{Results}

We used a yeast two-hybrid system to screen for NR3A-associated proteins in a human embryonic brain cDNA library using the full-length intracellular C-terminus as bait [16]. One of the 36 clones that we initially identified as interactors coded for the small GTPase Rheb, a 
Fig. 2. Characterization of the NR3Ac Rheb-binding domain. The strongest binding was of Rheb was observed to a central region between amino acids 967 and 1,039 (lanes 3-5). Some binding was observed to the N-terminal flanking region (amino acids 952-964, lane 2), while no binding was observed to the C-terminal flanking region (amino acids 1,034-115, lanes 9 and 10). Recombinant glutathioneS-transferase (GST), GST-NR3Ac or its truncated fusion proteins were incubated with Rheb-His protein and glutathione sepharose resin. The GST protein-bound resin was washed 3 times and the associated proteins were boiled and analyzed by gel electrophoresis and immunoblotting using anti-His (top gel) or anti-GST antibodies (bottom gel). This experiment was repeated three times with similar results.
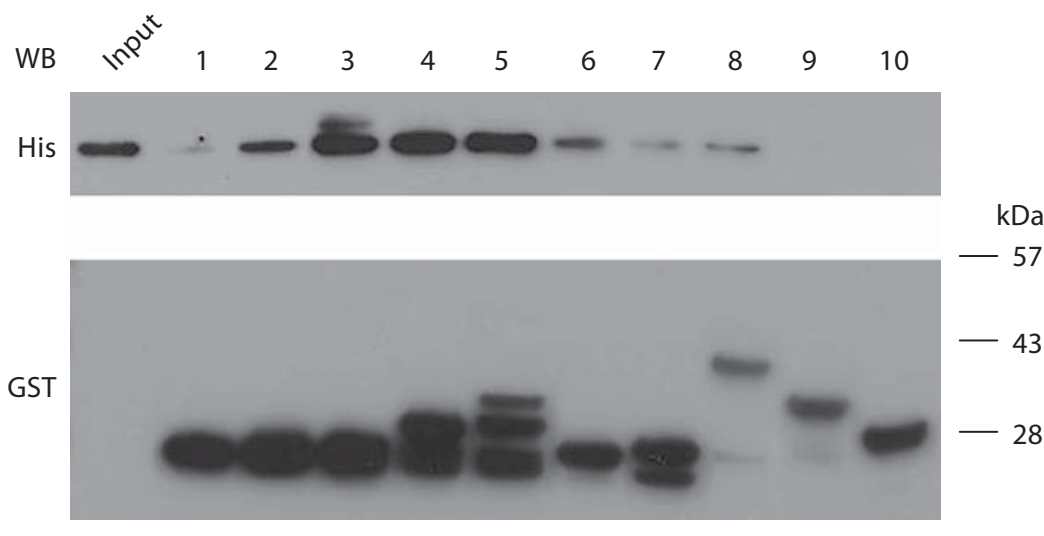

NR3A C-terminus 952

Lane 1: GST

Lane 2: GST-NR3A (952-964) -

Lane 3: GST-NR3A (967-987)

Lane 4: GST-NR3A (967-1004)

Lane 5: GST-NR3A (967-1039)

Lane 6: GST-NR3A (988-1004)

Lane 7: GST-NR3A (1012-1039)

Lane 8: GST-NR3A (988-1115)

Lane 9: GST-NR3A (1034-1115)

Lane 10: GST-NR3A (1069-1115)
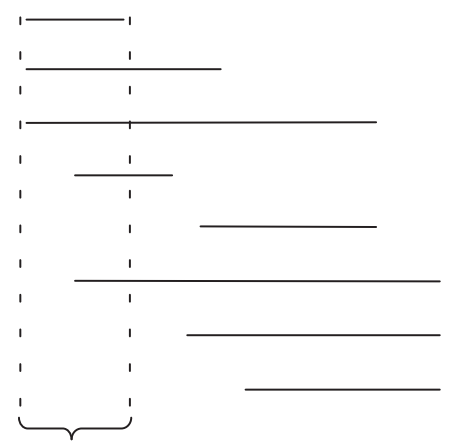

Central binding region member of the Ras superfamily of GTP-binding proteins $[17,18]$. Re-transformation of yeast cells confirmed that this clone interacted with NR3A and indicated that the carboxyl intracellular domain of the NR3A subunit appeared to contain a Rheb-binding site. We showed previously that the catalytic subunit of the serine-threonine protein phosphatase $2 \mathrm{~A}$ ( $\mathrm{PP} 2 \mathrm{~A}$ ) bound to the $\mathrm{N}$-terminal 37-amino-acid cassette of NR3Ac [16, 19].

To define the binding domain of Rheb of NR3Ac, we used various NR3Ac deletion constructs in both the yeast two-hybrid assay and in vitro protein-binding assays. First, we used the bait fragments, NR3Ac-5 and NR3Ac6 , that were used in our previous study [16] to identify the binding domain of the catalytic subunit of PP2A to assay for their binding activities to Rheb in yeast (fig. 1). We found that Rheb bound to both deletion constructs but the binding to NR3Ac-6 was significantly decreased compared to NR3Ac and NR3Ac-5 ( $p<0.001$ and $\mathrm{p}<$ 0.01 , one-way analysis of variance followed by Tukey's multiple comparison test; fig. 1). Next, we used in vitro protein-binding assays to further define the Rheb-binding domain of NR3Ac (fig. 2). Rheb appeared to bind most strongly to a central region of the NR3A C-terminal located between amino acids 967 and 1,039 (lanes 3-5) with much weaker binding to the $\mathrm{N}$-terminal flanking region (aa 952-964, lane 2). Rheb did not appear to interact with the very C-terminal flanking region (aa 1,0341,115 , lanes 9 and 10). These results indicate that the Rheb-binding domain of NR3Ac appears to overlap with but extend beyond the previously defined PP2A-binding domain of NR3A [16].

The Rheb-binding central region of the NR3A C-terminal located between amino acids 967 and 1,039 appeared to contain at least two sites that rendered it sensi- 
Fig. 3. Association of Rheb and NR3A in HEK293 cells and in the developing rat brain. a HEK293 cells were transiently transfected with the full-length NR3A alone or NR3A and Rheb-Myc. Lysates were immunoprecipitated with either anti-NR3A or antiMyc antibodies and separated by SDS-PAGE. Western blots of anti-NR3A-precipitated samples were probed with anti-Myc antibodies and vice versa. Detection of Rheb-Myc in the lanes precipitated with anti-NR3A and vice versa following co-transfection with NR3A and Rheb-Myc but not in lysates transfected with NR3Ac alone indicate that both proteins interact with each other in HEK293 cells. b Immunoprecipitation from crude membrane (CM) and synaptic plasma membrane (SPM) fractions (5 mg protein/sample) from rat brain at postnatal day 8 was performed using non-specific control IgG antibodies and anti-Rheb antibodies. The immunoprecipitates were analyzed by Western blotting with anti-NR3A antibodies. NR3A was detected when CM and SPM were subjected to immunoprecipitation with anti-Rheb antibodies (dark band in the two lanes on the left) or NR3A antibodies (third lane from left). No NR3A was detected when CM and SPM were subjected to immunoprecipitation with nonspecific IgG antibodies (right lane). Together, the results indicate that Rheb and NR3A associate in the brain and that the NR3A/Rheb complex is likely present at synapses. The examples shown are from the same Western blot and similar results were obtained in two additional experiments.

tive to proteolytic degradation as evident by the appearance of additional bands in lanes 4 and 5. Interestingly, estimation of the secondary structure of the Rheb-binding domain of NR3Ac using the Xtal program [20, 21] indicated the presence of a helix flanked by two loop regions consistent with the previous observation of high frequency of proteolytic cleavage sites in $\alpha$-helices and loops [22]. Whether or not proteolytic cleavage of NR3Ac occurs in neurons and might play a functional role remains to be investigated.

In order to investigate whether NR3A and Rheb also interacted in mammalian cells, we transiently transfected human embryonic kidney (HEK) 293 cells with the full-length NR3A and a Rheb/Myc fusion protein. Myc served as a 'tag' that allowed us to perform immunoprecipitation and Western blot experiments using anti-Myc antibodies. The results of these experiments showed that Rheb associated with NR3A in the HEK293 cells and formed a stable complex that could be immunoprecipitated using either anti-NR3A or anti-Myc antibodies.

Next, we determined whether Rheb also interacted with NR3A in the brain. We performed immunoprecipitation using an anti-Rheb antibody in crude membranes (CM) and synaptic plasma membranes (SPM) fractions from the developing rat brain. We detected NR3A protein in immunoprecipitates from both CM and SPM fractions

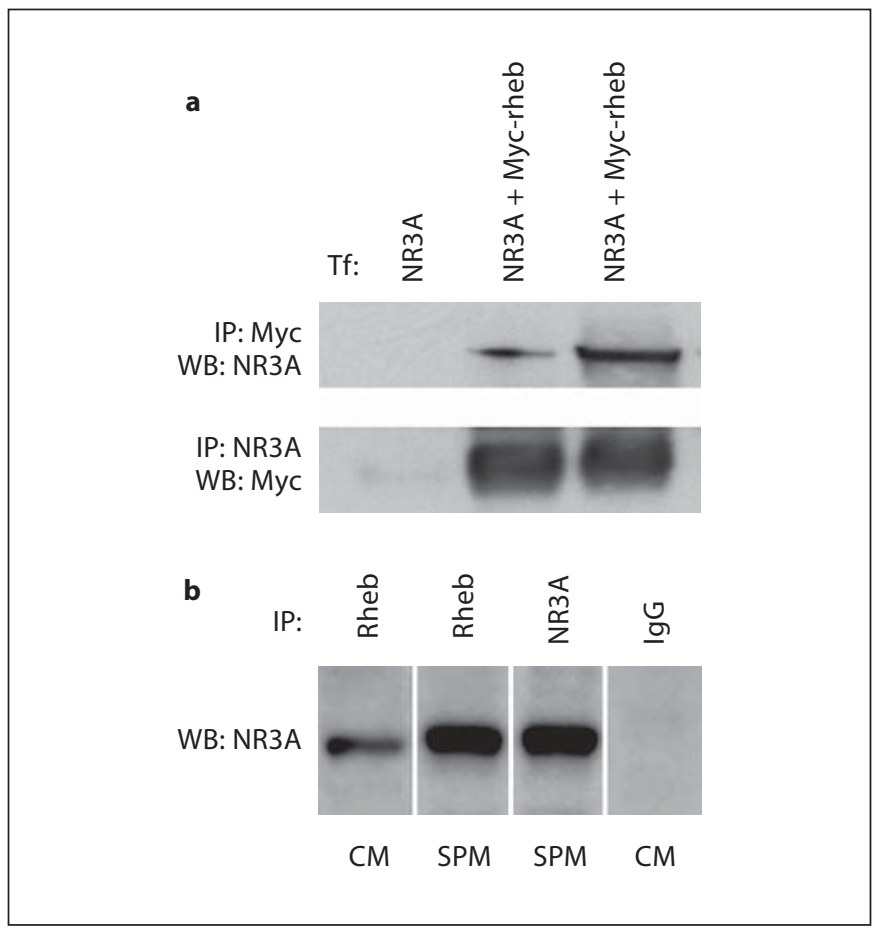

when anti-Rheb antibody was used but not in immunoprecipitates in which a nonspecific anti-rat IgG antibody was used as control (fig. 3). These results demonstrated that Rheb was associated with NR3A in the developing postnatal brain.

\section{Discussion}

Using a yeast two-hybrid system, we identified the small GTPase Rheb as an interacting protein of the NMDAR subunit NR3A. We confirmed that this interaction could also occur in mammalian cells by expressing recombinant Rheb and NR3A in HEK293 cells. We finally showed that Rheb and NR3A could be co-immunoprecipitated from synaptic plasma membranes from the developing rat brain. Using the yeast two-hybrid system and an in vitro protein-binding assay, we localized the Rheb-binding domain to the amino-terminal half of the NR3A intracellular C-terminus. This area overlaps with but exceeds the previously identified binding site of the catalytic subunit of PP2A [16].

Although Rheb was first identified as a growth factor and synaptic activity-regulated gene in the rat brain, its function remained obscure until the discovery that this small GTPase is an activator of the serine-threonine ki- 
nase mTOR. The mTOR kinase is part of two structurally distinct complexes, mTORC1 and mTORC2. Rheb is known to activate mTORC1. TORC1, but not TORC2, is sensitive to acute administration of rapamycin. The best characterized TORC1 substrates are the ribosomal S6 kinases 1 and 2 and the eukaryotic initiation factor $4 \mathrm{E}$ (eIF4E)-binding proteins (4E-BPs), critical components of the machinery involved in initiation of protein translation [4]. The mTORC1 complex has been shown to integrate inputs from various intra- and extracellular stimuli including nutrients (amino acids), growth factors, and energy status (AMP/ATP ratio) [15]. Our finding that Rheb directly binds to an NMDAR subunit is consistent with the notion that synaptic NMDAR activity is one of the signaling pathways converging on MTOR [23] based on the presence of eIF4E, 4E-BPs mTOR and S6K in dendrites and the inhibitory effects of rapamycin on the late phase of LTP in the hippocampus [24].

Rather than directly acting on MTORC1, several of the mTORC1 inputs negatively regulate the complex through the action of TSC1 and TSC2, also referred to as tuberin and hamartin, respectively. These two proteins form a complex that acts as GTPase-activating protein (GAP) towards Rheb, which under their influence converts GTP to GDP and becomes inactive. In the absence of functional TSC1/TSC2, Rheb becomes constitutively active and protein translation is freed from any regulatory constraints imposed on it by the signaling pathways converging on the TSC1/TSC2 GAP. Mutation of TSC1/TSC2 is the cause of tuberous sclerosis, a genetic disease characterized by the occurrence of benign tumors (hamartomas) in various organs including the brain, as well as neurological symptoms including seizures, cognitive deficits and autism. Thus, like FXS, tuberous sclerosis is a disease of dysregulated protein translation. In fact, recent research indicates that FMRP knockout mice exhibit dysregulated mTOR signaling [25].

Viewed together, there is convincing evidence that increased spine density is due to increased (dysregulated) protein synthesis as a consequence of increase activity of the mTOR-signaling cascade. As increased spine density has been observed in NR3A knockout mice, it is reasonable to hypothesize that genetic ablation of this subunit leads to dysregulated protein synthesis. Viewed in this context, it is tempting to speculate that NR3A normally sequesters synaptic Rheb and thus serves as a break of synaptic mTOR activity. Deletion of NR3A would release the break and increase mTOR activity, while overexpression of NR3A would engage the break and decrease mTOR activity. An increasing body of evidence strongly argues for a role of $\mathrm{mTOR}$ in the formation of long-lasting synaptic plasticity and memory $[4,26]$. Thus, the observed defect in memory consolidation in NR3A-overexpressing transgenic mice [10] is consistent with the sequestration of Rheb by NR3A and concomitant downregulation of mTORC1 activity and memory consolidation. Our results indicate that the Rheb-binding domain of NR3A partially overlaps with the previously identified binding domain of the catalytic subunit of PP2A [16]. As PP2A appeared to dissociate from NR3A upon NMDAR activation [16], it is possible that Rheb is sequestered by NR3A in an activity-dependent manner following the dissociation of PP2A. Along these lines, it is of note that regulation of $\mathrm{mTOR}$ signaling via the sequestration of Rheb by an interacting protein has recently been reported to couple glycolytic flux and glucose metabolism to mTORC1 activity [27].

\section{Acknowledgements}

We wish to thank Mina Chen and Xia Zhao (The State Key Laboratory of Bio-Therapy, West China Hospital, Sichuan University, Chengdu, 610041, China) for the anti-Rheb antibodies and Thanhthao Huynh for technical assistance. This work was supported by funding from the National Institutes of Health NINDS NS 31718 (F.E.J.), Office of the Director, National Institutes of Health GMS DP1 OD003347 (F.E.J.), the Tuberous Sclerosis Alliance (N.J.S. and F.E.J.), the Citizens United for Research in Epilepsy (N.J.S.), and core support from the Mental Retardation Developmental Disorders Research Center Grant NIH NICHHD P30 HD18655.
References
1 Feldman DE: Synaptic mechanisms for plasticity in neocortex. Annu Rev Neurosci 2009;32:33-55.

2 Malenka RC, Bear MF: LTP and LTD: An embarrassment of riches. Neuron 2004;44: $5-21$.

-3 Carlisle HJ, Kennedy MB: Spine architecture and synaptic plasticity. Trends Neurosci 2005;28:182-187.
4 Hoeffer CA, Klann E: mTOR signaling: at the crossroads of plasticity, memory and disease. Trends Neurosci 2010;33:67-75.

5 Cavara NA, Hollmann M: Shuffling the deck anew: how NR3A tweaks NMDA receptor function. Mol Neurobiol 2008;38:16-26.

6 Cull-Candy S, Brickley S, Farrant M: NMDA receptor subunits: diversity, development and disease. Curr Opin Neurobiol 2001;11: 327-335. 
7 Wong H-K, Liu X-B, Matos MF, Chan SF, Pérez-Otaño I, Boysen M, Cui J, Nakanishi N, Trimmer JS, Jones EG, Lipton SA, Sucher NJ: Temporal and regional expression of NMDA receptor subunit NR3A in the mammalian brain. J Comp Neurol 2002;450:303317.

8 Zhou C, Jensen F, Sucher N: Altered development of glutamatergic synapses in layer $\mathrm{V}$ pyramidal neurons in NR3A knockout mice. Mol Cell Neurosci 2009;42:419-426.

$\checkmark 9$ Das S, Sasaki YF, Rothe T, Premkumar LS, Takasu M, Crandall JE, Dikkes P, Conner DA, Rayudu PV, Cheung W, Chen HS, Lipton SA, Nakanishi N: Increased NMDA current and spine density in mice lacking the NMDA receptor subunit NR3A. Nature 1998;393: 377-381.

10 Roberts AC, Díez-García J, Rodriguiz RM López IP, Luján R, Martínez-Turrillas R, Picó E, Henson MA, Bernardo DR, Jarrett TM, Clendeninn DJ, López-Mascaraque L, Feng G, Lo DC, Wesseling JF, Wetsel WC, Philpot BD, Pérez-Otaño I: Downregulation of NR3A-containing NMDARs is required for synapse maturation and memory consolidation. Neuron 2009;63:342-356.

-11 Bassell GJ, Warren ST: Fragile X syndrome: loss of local mRNA regulation alters synaptic development and function. Neuron 2008;60: 201-214.

12 Bear MF, Dolen G, Osterweil E, Nagarajan N: Fragile X: Translation in action. Neuropsychopharmacology 2008;33:84-87.
13 Narayanan U, Nalavadi V, Nakamoto M, Pallas DC, Ceman S, Bassell GJ, Warren ST: FMRP phosphorylation reveals an immediate-early signaling pathway triggered by group I mGluR and mediated by PP2A. J Neurosci 2007;27:14349-14357.

14 Narayanan U, Nalavadi V, Nakamoto M, Thomas G, Ceman S, Bassell GJ, Warren ST: S6k1 phosphorylates and regulates fragile $\mathrm{X}$ mental retardation protein (FMRP) with the neuronal protein synthesis-dependent mammalian target of rapamycin (mTOR) signaling cascade. J Biol Chem 2008;283: 18478-18482.

15 Arsham AM, Neufeld TP: Thinking globally and acting locally with TOR. Curr Opin Cell Biol 2006; 18:589-597.

16 Chan SF, Sucher NJ: An NMDA receptor signaling complex with protein phosphatase $2 \mathrm{a}$. J Neurosci 2001;21:7985-7992.

17 Yamagata K, Sanders LK, Kaufmann WE, Yee W, Barnes CA, Nathans D, Worley PF: Rheb, a growth factor- and synaptic activityregulated gene, encodes a novel ras-related protein. J Biol Chem 1994;269:16333-16339.

18 Aspuria P-J, Tamanoi F: The Rheb family of GTP-binding proteins. Cell Signal 2004; 16 : 1105-1112.

19 Ma OK, Sucher NJ: Molecular interaction of NMDA receptor subunit NR3A with protein phosphatase 2A. Neuroreport 2004; 15:14471450

20 Slabinski L, Jaroszewski L, Rodrigues AP, Rychlewski L, Wilson IA, Lesley SA, Godzik A: The challenge of protein structure determination - lessons from structural genomics. Protein Sci 2007;16:2472-2482.
Slabinski L, Jaroszewski L, Rychlewski L, Wilson IA, Lesley SA, Godzik A: Xtalpred: a web server for prediction of protein crystallizability. Bioinformatics 2007;23:34033405.

-22 Igarashi Y, Eroshkin A, Gramatikova S, Gramatikoff K, Zhang Y, Smith JW, Osterman AL, Godzik A: Cutdb: a proteolytic event database. Nucleic Acids Res 2007; 35:D546-D549.

23 Li N, Lee B, Liu RJ, Banasr M, Dwyer JM, Iwata M, Li XY, Aghajanian G, Duman RS: mTOR-dependent synapse formation underlies the rapid antidepressant effects of NMDA antagonists. Science 2010;329:959964

24 Tang SJ, Schuman EM: Protein synthesis in the dendrite. Philos Trans R Soc Lond B Biol Sci 2002;357:521-529.

25 Sharma A, Hoeffer CA, Takayasu Y, Miyawaki T, McBride SM, Klann E, Zukin RS: Dysregulation of mTOR signaling in fragile X syndrome. J Neurosci 2010;30:694-702.

26 Weatherill DB, Dyer J, Sossin WS: Ribosomal protein $\mathrm{S} 6$ kinase is a critical downstream effector of the target of rapamycin complex 1 for long-term facilitation in aplysia. J Biol Chem 2010;285:12255-12267.

27 Lee MN, Ha SH, Kim J, Koh A, Lee CS, Kim JH, Jeon H, Kim DH, Suh PG, Ryu SH: Glycolytic flux signals to mTOR through glyceraldehyde-3-phosphate dehydrogenase-mediated regulation of Rheb. Mol Cell Biol 2009;29:3991-4001. 